\title{
Retrospective research of rice blast development in Krasnodar region
}

\author{
Dmitry Nartymov*, Elena Dubina, and Sergey Garkusha \\ Federal Scientific Rice Centre, Belozerny, 3, Krasnodar, 350921, Russia
}

\begin{abstract}
Today, rice blast remains the most dangerous disease, therefore, along with breeding developments, it is necessary to study the dependence of the pathogen's behavior on agroclimatic conditions. In addition, an understanding of the dynamics of blast development in the non-growing season is necessary. The studies conducted are aimed at establishing agroclimatic patterns that contribute to the development of the disease in the pre-growing and growing periods by analyzing the results of the implementation of the mathematical model. As a result of research, the dependence of the intensity of damage to rice crops on the intensity of environmental influences in the pre-growing season was established, which suggests that it is necessary to apply agrotechnological measures before sowing to reduce the phytosanitary load on plants and the environment.
\end{abstract}

\section{Introduction}

Blast development during the growing season of rice plants remains one of the most dangerous phenomena manifested during the cultivation of crops [1]. Breeding developments in the field of rice farming could significantly reduce the rate of infection with blast, but a significant role in the dynamics of the development of the pathogen Pyricularia oryzae Cav. [2 - 4] is played by agroclimatic conditions and agrotechnological measures $[5,6]$. Therefore, today, to prevent and combat blast, it is necessary to monitor agroclimatic conditions and develop approaches and methods to combat the pathogen based on meteorological data processing.

In 2019, in the laboratory of information, digital and biotechnologies of Federal Scientific Rice Centre, within the framework of state task No. 0494-2019-0001, scientific work was carried out to develop mathematical algorithms that describe the dynamics of blast development. Based on the results of the studies, a model was developed [7], which allows one to assess the dynamics of the development of the pathogen during the growing season of rice plants. Based on agroclimatic data obtained under homogeneous conditions (geographical localization, agrotechnical measures), the model allows one to obtain an assessment of the dynamics of blast development during any period. Thus, the use of this model allows a retrospective study of a ten-year cycle of agricultural production in the Krasnodar region.

* Corresponding author: dimnortey@mail.ru 


\section{Aim and objectives of the study}

The aim of the study is to study climatic conditions conducive to the development of rice blast on the territory of agricultural land of Krasnodar region. To conduct the study, it is necessary to implement a model of the dynamics of rice blast development on the data of agroclimatic conditions, actually established during several pre-growing and growing periods, and to identify patterns that affect the pathogenicity of blast.

\section{Methods of research}

In the behavior of a retrospective study, the uniformity of data on a number of conditions is important. This approach makes it possible to compare the results of processing data obtained in different periods (retrospectively).

In the framework of this work, it is necessary to implement a model of the dynamics of blast development on the climatic data of several periods. The homogeneity condition for such data is geographical localization [8]. Therefore, for the research, data recorded at a meteorological station located in Slavyansk-on-Kuban were selected. The choice of data is due to the fact that the meteorological station has the location closest to the geographical center of the rice-growing area of Krasnodar region [9].

To assess the pathogenicity of rice blast at different periods of time, we used the data on the damage to rice crops by blast provided by the branch of the Federal State Budgetary Institution Rosselkhoztsentr in the Krasnodar region. The weighted average percentage of the spread and development of the pathogen informatively describes the intensity of blast development in a certain period.

It is known that the development of generations of Pyiricularia oryzae Cav. Pathogen occurs throughout the entire growing season of rice plants and is directly dependent on agroclimatic conditions. In addition, after the end of the growing season (harvesting), spores (conidia) of blast can be retained on crop residues, soil and plants developing in close proximity to areas where rice is cultivated $[10,11]$. Under certain conditions, individual conidia can give rise to a new generation and create an increased infectious background by the beginning of the next growing season. Therefore, in the framework of the research work, two periods were conditionally distinguished: pre-growing and growing. The pre-growing period originates after harvesting the previous growing period and ends with the beginning of the current growing period. The growing period is limited to days from sowing to harvesting [12]. On the greater territory of Krasnodar region, sowing dates are set by the end of April, and harvesting ends in September [13], so the pre-growing period is separated by the beginning of October and the end of April, the remaining days belong to the growing period.

The intensity of climatic conditions that directly affect the development of rice blast both during the growing season and the pre-growing season is described by implementing a model of the dynamics of blast development on meteorological data recorded during this period. The implementation of the model makes it possible to identify time intervals that contribute to plant infection and the development of a pathogen, as well as to evaluate the intensity of the pathogen exposure during this time period, expressed as a percentage of probability (\%). Such time periods are called excess, and the number of excesses during the study period describes the intensity of the manifestations of rice blast [14]. Estimating the number of excesses during the pre-growing and growing periods will help to identify the intensity of the influence of the environment and agroclimatic conditions on the dynamics of the pathogen Pyricularia oryzae Cav. [15].

As part of the research work, the data of meteorological observations recorded at a meteorological station in the city of Slavyansk-on-Kuban, and the data on the damage to 
rice crops by blast from 2009 to 2019 were selected. On the data of each pre-growing and growing periods, a model of the dynamics of blast development was implemented and the number of excesses that appeared during the month and then the entire period was calculated. This approach made it possible to compare the implementation data and the actual data on the damage of crops and to analyze the intensity of the environmental impact on a monthly basis.

\section{Results and discussion}

As a result of studies and analysis of the data of the pre-growing period, it was revealed that the greatest number of excesses was observed in the pre-vegetation period of 2013, the smallest amount was noted in the same period of 2018. It is important to note that in December of the same period of 2013, the maximum number of excesses was revealed -4 . Averaged indicators indicate that in the period from October to December there is the largest number of excesses during the pre-vegetation period. However, in some cases, excesses are observed in March and April.

The results of calculating the number of excesses and crop damage with blast in the pregrowing season are shown in table 1 . It should be noted that periods $10 \ldots 04$ correspond to the months of the year, namely 10 - October, 11 - November, 12 - December, etc.

An analysis of the data indicates that during the period from October to December, climatic conditions contribute to blast development, therefore, we can assume the development and maturation of the pathogen Pyricularia oryzae Cav. on crop residues and plants [16]. In addition, in March and April there is also a high probability of the development of pathogen generations already before the start of the growing season. Such conditions can greatly increase the area's contamination before sowing and create an unfavorable phytosanitary situation during the growing season [17].

Table 1. The number of excesses and data on the damage of crops in the pre-growing season

\begin{tabular}{|c|c|c|c|c|c|c|c|c|c|c|}
\hline \multirow{2}{*}{ Year } & \multicolumn{7}{|c|}{ Month } & \multirow{2}{*}{ Total } & \multicolumn{2}{|c|}{$\begin{array}{l}\text { Average weighted } \\
\text { percent, } \%\end{array}$} \\
\hline & 10 & 11 & 12 & 01 & 02 & 03 & 04 & & Spread & $\begin{array}{c}\text { Develop } \\
\text { ment }\end{array}$ \\
\hline 2009 & 0 & 1 & 0 & 1 & 0 & 2 & 1 & 5 & 9.5 & 0.2 \\
\hline 2010 & 2 & 2 & 0 & 0 & 0 & 2 & 3 & 9 & 30.0 & 2.3 \\
\hline 2011 & 2 & 0 & 0 & 1 & 0 & 1 & 3 & 7 & 10.9 & 1.2 \\
\hline 2012 & 4 & 0 & 3 & 2 & 2 & 0 & 0 & 11 & 5.3 & 0.2 \\
\hline 2013 & 1 & 3 & 4 & 1 & 1 & 2 & 0 & 12 & 20.4 & 5.7 \\
\hline 2014 & 0 & 1 & 1 & 1 & 1 & 0 & 0 & 4 & 5.1 & 0.4 \\
\hline 2015 & 1 & 2 & 1 & 1 & 0 & 1 & 0 & 6 & 4.5 & 0.14 \\
\hline 2016 & 1 & 2 & 0 & 0 & 0 & 1 & 1 & 5 & 3.8 & 0.3 \\
\hline 2017 & 2 & 2 & 1 & 1 & 0 & 0 & 0 & 6 & 3.8 & 0.2 \\
\hline 2018 & 0 & 1 & 0 & 0 & 0 & 1 & 0 & 2 & 3.2 & 0.2 \\
\hline 2019 & 1 & 2 & 2 & 1 & 0 & 0 & 0 & 6 & 4.6 & 0.5 \\
\hline $\begin{array}{l}\text { Mean } \\
\text { value }\end{array}$ & 1.4 & 1.5 & 1.2 & 0.8 & 0.4 & 0.8 & 0.7 & 6.8 & - & - \\
\hline Max. & 4 & 3 & 4 & 2 & 2 & 2 & 3 & 12 & - & - \\
\hline
\end{tabular}

A comparative analysis of data on the number of excesses and damage to rice crops by blast is presented in Figure 1. 


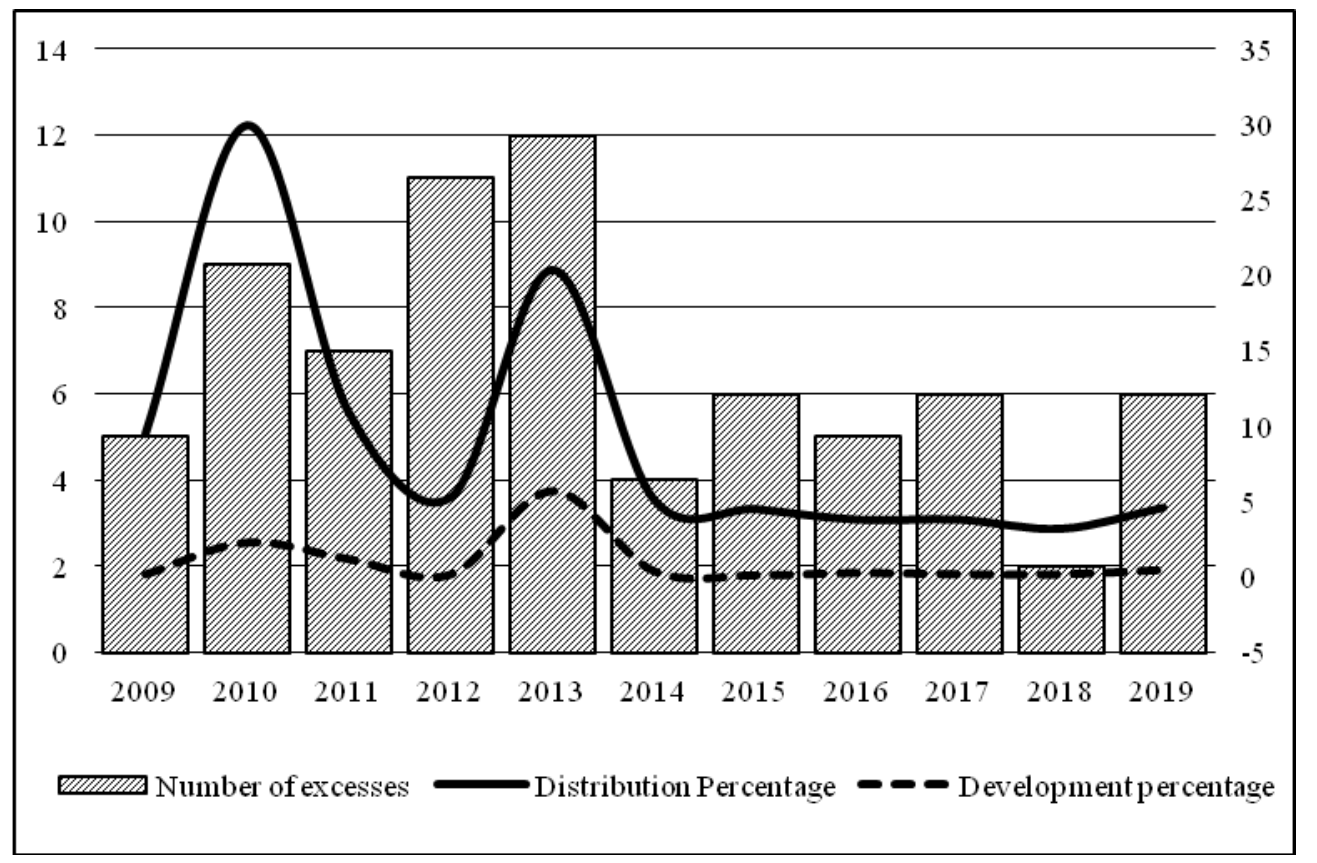

Fig. 1. Comparative analysis of data on the number of excesses and damage of rice crops by blast during the pre-growing period

The diagram shows that high values of crop damage occur in years, in the pre-growing season of which a high number of excesses is noted (8-12). At the same time, years with a low number of excesses in the pre-growing season show a low level of crop damage. Thus, a relative correlation of the number of detected excesses and the level of damage to rice crops can be noted.

Studies of the growing period data showed that the largest number of excesses (18) was observed in the growing season of 2010 and 2011, in addition, a high number of excesses was noted in 2009, 2012 and 2013. The largest number of excesses (6) was recorded in June and July, while in August 2011 the maximum number of excesses per month was 7 which is more likely the exception, because the average value for this month is 1.1 .

The results of calculating the number of excesses and the data on damage of crops by blast during the growing season are shown in table 2 .

Table 2. The number of excesses and the data on the damage of crops during the growing season

\begin{tabular}{|c|c|c|c|c|c|c|c|c|}
\hline & \multicolumn{5}{|c|}{ Month } & \multirow{2}{*}{ Total } & \multicolumn{2}{|c|}{$\begin{array}{c}\text { Average weighted } \\
\text { percent, \% }\end{array}$} \\
\cline { 2 - 5 } \cline { 8 - 9 } Year & 05 & 06 & 07 & 08 & 09 & & Spread & $\begin{array}{c}\text { Develop } \\
\text { ment }\end{array}$ \\
\hline 2009 & 2 & 4 & 6 & 2 & 1 & 15 & 9.5 & 0.2 \\
\hline 2010 & 3 & 6 & 6 & 1 & 2 & 18 & 30.0 & 2.3 \\
\hline 2011 & 2 & 4 & 4 & 7 & 1 & 18 & 10.9 & 1.2 \\
\hline 2012 & 2 & 1 & 3 & 3 & 3 & 12 & 5.3 & 0.2 \\
\hline 2013 & 1 & 4 & 5 & 0 & 1 & 11 & 20.4 & 5.7 \\
\hline 2014 & 1 & 1 & 5 & 0 & 1 & 8 & 5.1 & 0.4 \\
\hline 2015 & 0 & 5 & 1 & 0 & 0 & 6 & 4.5 & 0.14 \\
\hline 2016 & 0 & 3 & 2 & 0 & 1 & 6 & 3.8 & 0.3
\end{tabular}


Continuation of the table 2

\begin{tabular}{|c|c|c|c|c|c|c|c|c|}
\hline 2017 & 2 & 1 & 4 & 0 & 2 & 9 & 3.8 & 0.2 \\
\hline 2018 & 1 & 2 & 1 & 0 & 1 & 5 & 3.2 & 0.2 \\
\hline 2019 & 1 & 3 & 1 & 0 & 0 & 5 & 4.6 & 0.5 \\
\hline $\begin{array}{c}\text { Mean } \\
\text { value }\end{array}$ & 1.3 & 3.0 & 3.2 & 1.1 & 1.1 & 9.8 & - & - \\
\hline Max. & 3 & 6 & 6 & 7 & 3 & 18 & - & - \\
\hline
\end{tabular}

An analysis of the data on the growing season shows that the amount of excess and the intensity of the lesion are related, but have a weak correlation between each other. So in years with a high number of excesses during the growing season there is a high damage of rice crops by blast, and in years with a low number of excesses, the lesion remains at a rather low level.

The comparative analysis presented in Figure 2 confirms the assumption that high values of crop damage are associated with an increased number of excesses during the growing season, but they have a rather weak correlation [18].

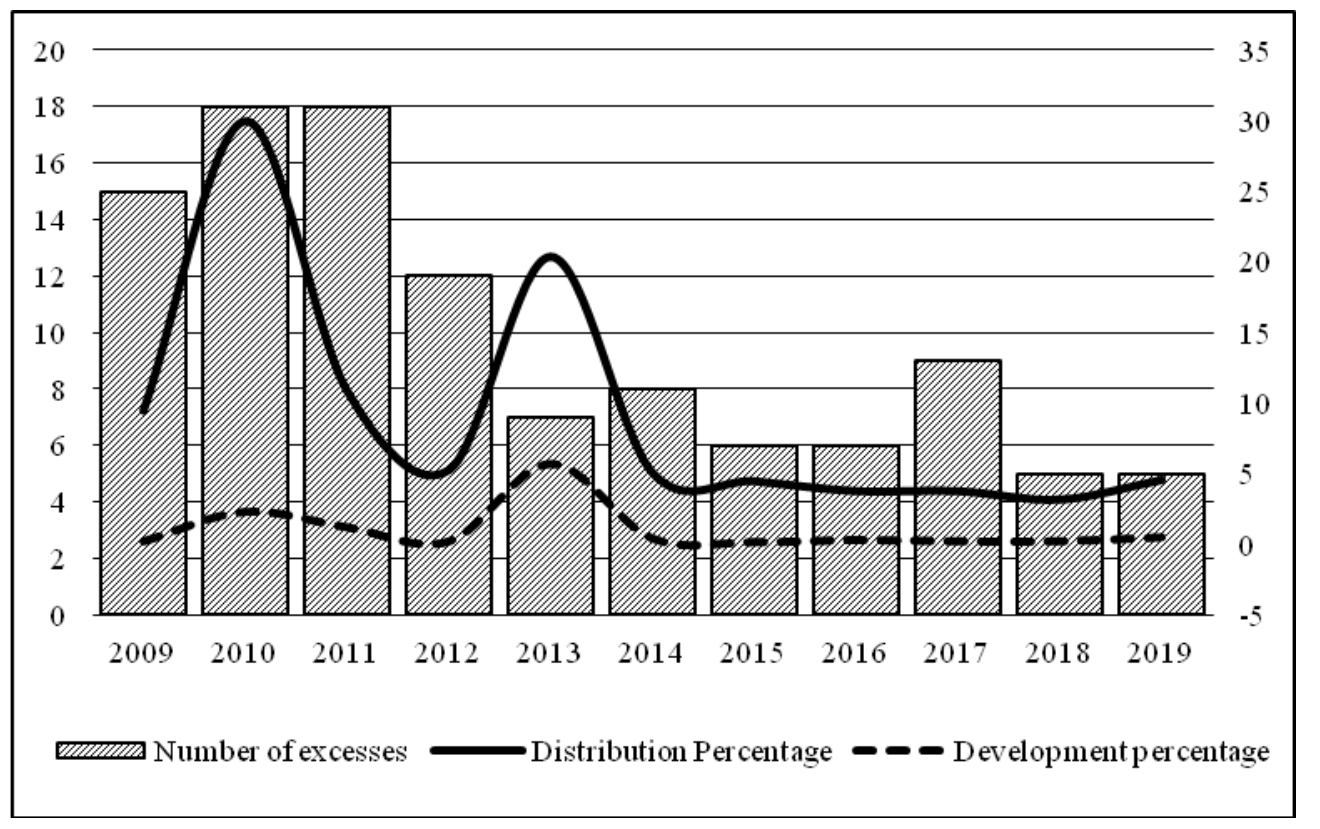

Fig. 2. A comparative analysis of the data on the number of excesses and damage to rice crops by blast during the growing season

The data obtained make it possible to analyze the average and maximum number of excesses identified during each month of the pre-growing and growing periods. A comparative analysis of the data is presented in Figure 3 in the form of a petal diagram. This approach helps to track the cyclical dynamics of changes in the number of identified excesses during the year. 


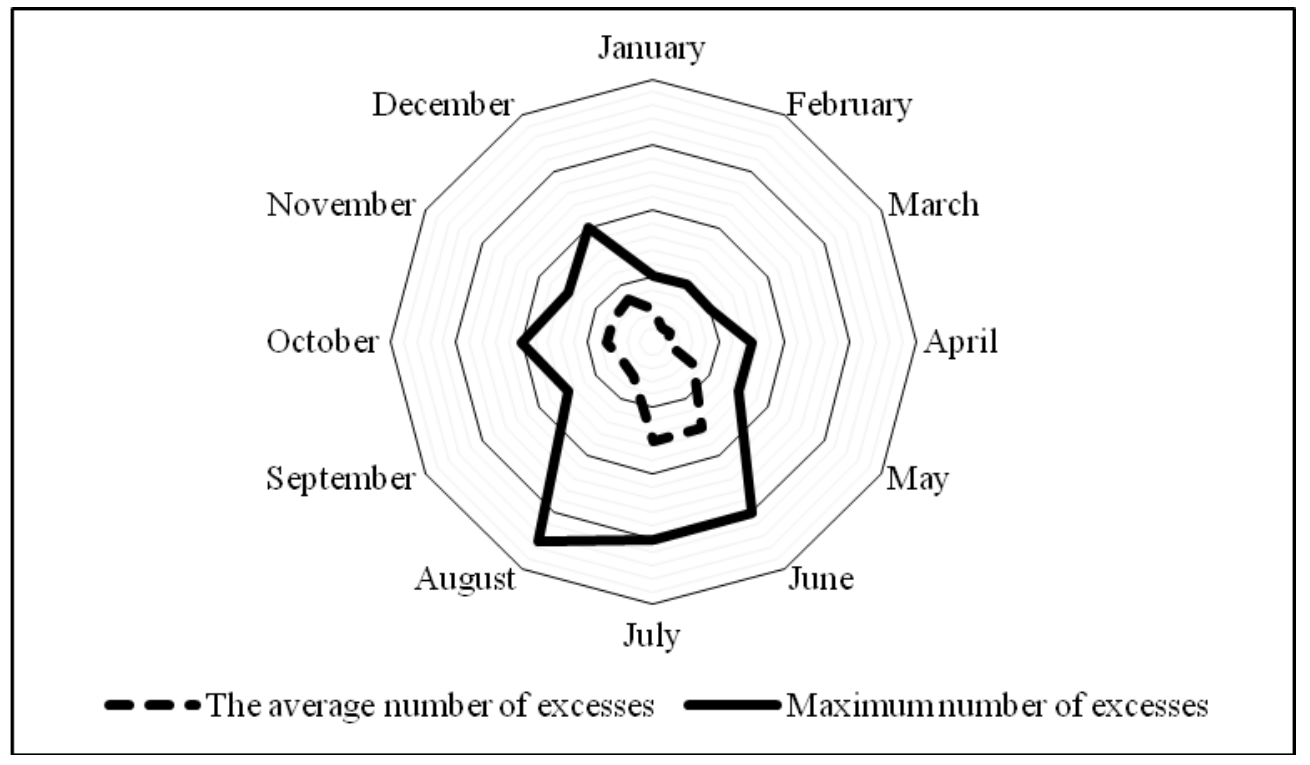

Fig. 3. Comparative analysis of the average and maximum number of excesses

It can be seen from the obtained diagram that the maximum values are concentrated in the summer months. Most of the excesses occur in June and July of the growing season. In addition, it is worth noting that in the days of August there is also a high probability of manifestations of excesses. At the same time, quite frequent manifestations, although in a weak form, were noted between October and December.

\section{Conclusions}

As a result of retrospective studies, the nature of the influence of agroclimatic conditions on the dynamics of the distribution and development of Pyricularia orizae Cav. pathogen was revealed on the territory of Krasnodar region during the pre-growing and growing periods.

The research data showed that the intensity of agroclimatic factors on the dynamics of blast development in the pre-growing and growing periods varies. While the number of excesses detected during the growing season poorly describes the damage to rice crops, the data on the number of excesses during the pre-growing season and the intensity of damage to rice crops have a correlation. Thus, to prevent the development of a pathogen, it is necessary to monitor agro-climatic conditions both during the rice growing season and in the pre-growing season. Such an approach should be accompanied by the study of agroclimatic factors in the pre-growing period, including the use of a model of the dynamics of rice blast development. In addition, in all territories of Krasnodar region used for agricultural production of rice crops, it is necessary to continuously monitor agroclimatic data using a model of the dynamics of pathogen development in the pregrowing and growing periods [19-21]. This will allow sufficient pre-sowing measures to be taken to reduce the phytosanitary load on plants and the environment during the growing season [22-26]. 


\section{Authorship criteria}

The authors of the article confirm that D.V. Nartymov has $90 \%$ of authorship rights, E.V. Dubina $-5 \%$, S.V. Garkusha $-5 \%$ and are equally responsible for plagiarism.

\section{References}

1. N.A. Sasova, Pl. prot. and quar., 6, 48-50 (2014).

2. A. Amei, S. Lee, K. S. Mysore and Yu. Jia, G3: Gen., Genom., Genetics., 4(12), 2425-2432 (2014) DOI: https://doi.org/10.1534/g3.114.014969

3. Bechet M., Caradec T., Hussein W., Abderrahmani A. et. al., Appl Microbiol. Biotech., 95, 593-600 (2012) DOI: https://link.springer.com/article/10.1007/s00253-0124181-2

4. K. Spence et al. BMC Plant Biol., 14(130), 16-17 (2014) DOI: http://www.biomedcentral.com/1471-2229/14/130

5. Aver'yanov, T. Andreevna, T. Belozerskaya, N. Belozerskaya, In book: Biocommunication of Fungi, 261-271 (2012) DOI: https://www.sci-hub.tw/10.1007/97894-007-4264-2_17

6. N.M. Gopalo, M.S. Sokolov, I.A. Kostenko, Biol. Pl. prot., 650-659 (2010).

7. J.M. Bonman, Euph. 63, 115-123 (1992) DOI: https://doi.org/10.1007/BF00023917

8. D. Nartymov, E. Dubina, S. Garkusha and N. Istomin, E3S Web Conf. V. 135, 6 (2019) DOI: https://doi.org/10.1051/e3sconf/201913501095

9 N.A. Evsyukov, Yu.G. Sokolov, Pl. prot. and quar., 10, 40-41 (2010)

10. R.Yu. Danilov, V.Ya. Ismailov, V.A. Tretyakov, O.Yu. Kremneva, Yu.V. Shumilov, A.A. Rizvanov, V.V. Krivoshein, I.A. Kostenko, Mat. of the II All-Russian entific conference with international participation "The use of remote sensing of land in

agriculture", 367-374 (2018)

11. E.V. Dubina, M.G. Ruban, Yu.V. Aniskina, I.A. Shilov, N.S. Velishaeva, P.I. Kostylev, Yu.A. Makukha, D.A. Pischenko, Ach. of Sc. and Tech. of AIC, 32/10, 19-23 (2018)

12. S. J. S. Rama Devi, K. Singh, B. Umakanth et al., Rice Sci., 22(6), 300-308 (2015) DOI: http://www.ricescience.org//EN/10.1016/S1672-6308(14)60308-5

13. E.V. Dubina, Z.M. Mukhina, E.M. Kharitonov, V.N. Shilovskiy, E.S. Kharchenko,

L.V. Esaulova, N.N. Korkina, E.P. Maximenko, I.B. Nikitina, Rus. J. of Gen., 51/8,

752-756 (2015) DOI: https://link.springer.com/article/10.1134\%2FS1022795415060058

14. Ma Z, WangL, ZhaoM, Gu S, WangC,ZhaoJ, et al., PLoSONE, 15(1), 1-20 (2020)

DOI: https://doi.org/10.1371/journal.pone.0227470

15. T.S. Zakharenkova, A.A. Aver'yanov, T.D. Pasechnik, V.P. Lapikova, C.J. Baker, Rus. Jour. of Pl. Physiol. 57(5), 615-619 (2010) DOI: https://link.springer.com/content/pdf/10.1134/S1021443710050031.pdf

16.A. Kovalevskaya, V.N. Lelyavskaya, A.A. Kovalyeva, Pl. prot. and quar., 5, 24-26 (2013)

17. T.V. Dudchenko, Pl. prot. and quar., 8, 29-32 (2017)

18. P.I. Kostylev, K.S. Artyukhin, Weeds, diseases and pests of rice agrocenoses of the south of Russia, 347 (2010)

19. E.V. Dubina, V.N. Shilovsky, P.I. Kostylev, M.G. Ruban, A.M. Ogly, Plant Biotech. and Breed. 2(1), (2019) DOI: https://doi.org/10.30901/2658-6266-2019-1-16-23

20. E.V. Dubina DNA-technologies (molecular marking) in rice breeding and seed production of vegetable crops, Ph.D. thesis, 275 (2019) DOI: https://vak.minobrnauki.gov.ru/advert/100041696

21. Precision agriculture technology for crop farming, Ed. by Qin Zh., 282 (2016). 
22. K. Yamamoto, T. Togami, N.Yamaguchi, Sensors 17(11), 2557 (2017) DOI: https://doi.org/10.3390/s17112557

23. Kurtulmus, F.; Lee, W.S.; Vardar, A. Immature peach detection in colour images acquired in natural illumination conditions using statistical classifiers and neural network. Precis. Agric., 15, 57-79 (2013) DOI: https://doi.org/10.1007/s11119-013-9323-8

24. Chekmarev V.V., Zeleneva Yu.V., Levin V.A., Firsov V.F., Yakunina I.V. A methodology for compiling a short-term forecast for the development of rusty diseases of cereals (for the conditions of the Tambov region, Tambov, 30 p. (2014).

25. Hughes D.P. Salathe M., 2015, arXiv:1511.08060.

26. Chen X., Ronald P.C., Trend. Plantscie., 16(8), 451-459 (2011) https://doi.org/10.1016/j.tplants.2011.04.003 